\title{
Noninvasive determination of inspiratory pressure in patients with spinal cord injury: what is the best method?***
}

\author{
Determinação não-invasiva da pressão inspiratória em pacientes \\ com lesão medular traumática: qual é o melhor método? \\ Andrea Ponte Rocha, Sergio Ricardo Menezes Mateus, \\ Thomas Anthony Horan, Paulo Sérgio Siebra Beraldo
}

\begin{abstract}
The aim of the study was to evaluate the performance of sniff nasal inspiratory pressure (SNIP) and MIP in individuals with spinal cord injury. We evaluated 26 patients with spinal cord injury. Mean FVC in those with tetraplegia was $52 \pm 19 \%$ of predicted, compared with $78 \pm 23 \%$ of predicted in those with paraplegia $(p<0.05)$. In contrast, the percentage of predicted SNIP was lower in those with tetraplegia than in those with paraplegia $(p<0.05)$. $\ln$ all participants, SNIP correlated significantly with the level of the injury $(r=0.489 ; 95 \% \mathrm{Cl}: 0.125-0.737)$. The impact that the greater discriminatory power of SNIP has on the diagnosis of impaired pulmonary function in spinal cordinjured patients should be investigated further.
\end{abstract}

Keywords: Spinal cord injuries; Respiratory function tests; Respiratory muscles; respiratory paralysis.

\section{Resumo}

0 objetivo deste estudo foi verificar o desempenho da pressão inspiratória nasal durante o fungar (Plnas) e da Plmáx em indivíduos com lesão medular traumática. Foram avaliados 26 pacientes com lesão medular traumática. Os pacientes tetraplégicos e paraplégicos exibiram diferentes médias do percentual do previsto da CVF, respectivamente, $52 \pm 19 \%$ e $78 \pm 23 \%(p<0,05)$. Ao contrário da Plmáx, o percentual do previsto médio da Plnas foi inferior nos tetraplégicos $(\mathrm{p}<0,05)$ e, em todos os participantes, a correlação com o nível da lesão foi significativa ( $r=0,489$; 1C95\%: 0,125-0,737). 0 impacto do melhor discernimento da Plnas no diagnóstico das alterações da função inspiratória de pacientes com lesão medular traumática merece ser aprofundado.

Descritores: Traumatismos da medula espinal; Testes de função respiratória; Músculos respiratórios;

Paralisia respiratória.

Pulmonary complications are responsible for elevated morbidity and mortality rates in tetraplegic patients. ${ }^{(1)}$ Spinal cord injury (SCl) can cause weakness and respiratory muscle paralysis in varying degrees, depending on the level and completeness of injury. ${ }^{(2,3)}$ The traditional investigations used in $\mathrm{SCl}$ patients are spirometry and determination of lung volumes. However, various factors can influence MIP and MEP results, ${ }^{(4-7)}$ and the value of MIP as an index of inspiratory power has been questioned. ${ }^{(6)}$ One alternative is determination of sniff nasal inspiratory pressure (SNIP). To date, there have been no clinical studies evaluating the use of SNIP in patients with $\mathrm{SCl}$. However, in patients with other neuromus- cular diseases, the prognostic value of SNIP for the evaluation of diaphragm strength has been shown to be comparable to that of nonvolumetric and invasive tests. ${ }^{(8-11)}$ The determination of SNIP is a rapid, easily executed procedure, and the equipment required is portable. To examine the hypothesis that SNIP can detect reduced inspiratory muscle strength in $\mathrm{SCl}$ patients, we compared SNIP, MIP and other pulmonary function parameters in $\mathrm{SCl}$ patients presenting total loss of motor function, stratifying the sample according to the level of the injury.

From June to October of 2005, $26 \mathrm{SCl}$ patients were evaluated at the Hospital SarahBrasilia. The inclusion criteria were as follows:

\footnotetext{
* Study carried out at the SARAH Center for Study and Research, SARAH Network of Rehabilitation Hospitals, SARAH-Brasilia, Brasilia, Brazil.

Correspondence to: Paulo Sérgio Siebra Beraldo. SMPW Q 18, Conjunto 5, Lote 3, casa H, CEP 71741-805, Brasília, DF, Brasil.

Tel 5561 3319-1424. Fax 5561 3319-1538. E-mail: beraldo8@terra.com.br or pauloberaldo@sarah.br

Financial support: None.

Submitted: 25 February 2008. Accepted, after review: 1 September 2008.

**A versão completa em português deste artigo está disponivel em www.jornaldepneumologia.com.br
} 
being male; being over 16 years of age; presenting complete cervical or thoracic motor lesion between $\mathrm{C} 5$ and $\mathrm{T} 12$ (American Spinal Injury Association grade $\mathrm{A}$ or $\mathrm{B})^{(12)}$; and being clinically stable. The following exclusion criteria were applied: having any systemic disease; requiring ventilatory support; and presenting nasal congestion or respiratory allergies. The patients were divided into two groups, based on the level of the injury (cervical or thoracic, corresponding to the tetraplegic and paraplegic patients, respectively). The two groups were similar in terms of clinical and demographic characteristics (Table 1).

The research protocol was approved by the Ethics Committee of the Hospital Sarah-Brasilia, and all patients gave written informed consent.

The protocol consisted of spirometry, maximal respiratory pressure determination and SNIP measurements. Subjects were tested individually during a single afternoon session while seated in their own wheelchair. Spirometry (MasterScope; Jaeger, Hoechberg, Germany) was conducted according to the American Thoracic Society standards, ${ }^{(13)}$ adjusted for $\mathrm{SCl}$ patients. ${ }^{(14)}$ Subsequently, maximal respiratory pressures were measured using a Micro Medical respiratory pressure meter (Micro Medical Ltd, Kent, UK) in a random sequence. The device incorporates a standard leak to avoid glottic closure at the moment of inspiratory and expiratory efforts. The data obtained were analyzed using the PUMA respiratory pressure database and analysis software, version 1.4 (http://puma.princeton.edu).

For the maximal respiratory pressure measurements, patients breathed through a flange-style mouthpiece with nasal clips and produced an effort of at least 2 seconds in duration. Measurements of MIP were obtained near residual volume, whereas those of MEP were obtained near total lung capacity. ${ }^{(7,15)}$ The SNIP was obtained near functional residual capacity using a plug adjusted to fit one nostril of the participants, while the other nostril was manually closed by the technician. All MIP, MEP and SNIP maneuvers were performed four times, with intervals of at least $60 \mathrm{~s}$ between each measurement. The highest values were recorded. For SNIP measurements, the procedure was performed twice in each nostril. For spirometry, we adopted the predicted value equations of Pereira et al. ${ }^{(16)}$; for MIP and MEP, we adopted those of Neder
Table 1 - Means (standard deviation) of groups characteristics and observed and percentage of predicted of spirometric parameters, MEP and MIP mouth pressures and sniff nasal inspiratory pressure (SNIP).

\begin{tabular}{|c|c|c|}
\hline \multirow[t]{3}{*}{ Parameter } & Cervical & Thoracic \\
\hline & $\mathrm{C} 5-\mathrm{C} 8$ & $\mathrm{~T} 1-\mathrm{T} 12$ \\
\hline & $\mathrm{n}=10$ & $\mathrm{n}=16$ \\
\hline \multicolumn{3}{|l|}{ Age, years } \\
\hline mean & $29.2(8.9)$ & $26.7(8.0)$ \\
\hline range & $19-45$ & 17-37 \\
\hline \multicolumn{3}{|c|}{ Body mass index, $\mathrm{kg} / \mathrm{m}^{2 a}$} \\
\hline mean & $22.3(3.7)$ & $24.8(4.9)$ \\
\hline range & $16-25$ & $18-35$ \\
\hline \multicolumn{3}{|c|}{ Time since injury, months ${ }^{b}$} \\
\hline mean & $21.8(16.9)$ & $23.1(28.4)$ \\
\hline range & $2-55$ & 5-117 \\
\hline $\begin{array}{l}\text { Completeness of } \\
\text { injury, ASIA A/B }\end{array}$ & $9 / 1$ & $16 / 0$ \\
\hline \multicolumn{3}{|l|}{ FVC, L } \\
\hline obs & $2.5(0.8)^{*}$ & $4.0(1.4)$ \\
\hline \%pred & $51.9(18.9)^{*}$ & $78.0(23.3)$ \\
\hline \multicolumn{3}{|l|}{$\mathrm{FEV}_{1}, \mathrm{~L}$} \\
\hline obs & $2.3(0.8)^{*}$ & $3.4(1.2)$ \\
\hline \%pred & $55.4(20.7)^{*}$ & $79.6(24.9)$ \\
\hline \multicolumn{3}{|l|}{$\mathrm{FEV}_{1} / \mathrm{FVC} \%$} \\
\hline obs & $84.8(20.8)$ & $87.2(10.8)$ \\
\hline \multicolumn{3}{|l|}{ MEP, $\mathrm{cmH}_{2} \mathrm{O}$} \\
\hline obs & $68.2(23.1)$ & $97.9(45.0)$ \\
\hline \%pred & $48.4(17.0)$ & $64.3(32.4)$ \\
\hline \multicolumn{3}{|l|}{$\mathrm{MIP}, \mathrm{cmH}_{2} \mathrm{O}$} \\
\hline obs & $71.7(28.9)$ & $92.9(30.9)$ \\
\hline \%pred & $54.8(22.5)$ & $69.3(22.9)$ \\
\hline \multicolumn{3}{|l|}{ SNIP, $\mathrm{cmH}_{2} \mathrm{O}$} \\
\hline obs & $68.5(23.2)^{*}$ & 98.4 (33.9) \\
\hline \%pred & $60.0(20.1)^{* * *}$ & $85.2(29.5)$ \\
\hline
\end{tabular}

Obs: observed; \%pred: percentage of predicted; ASIA: American Spinal Injury Association; SNIP: sniff nasal inspiratory pressure. ${ }^{a}$ Height was determined by dividing arm span by 1.06 and thus calculating BMl in order to select predicted spirometry values. 'bess than 6 months after acute injury in 3 patients: one in the cervical group (C6, 2 months); and two in the thoracic group (T3 and T4, 5 months for both). ${ }^{*} \mathrm{p}<0.05$ vs. thoracic group; ${ }^{* *} \mathrm{p}<$ 0.001 vs. thoracic.

et al. ${ }^{(15)}$; and, for SNIP, we adopted those of Uldry and Fitting. ${ }^{(17)}$

The statistical tests were restricted to Student's t-tests, since all variables presented normal distribution of data. In the analysis of correlation (Pearson's), we considered the most cranial level of loss of motor function. We arbitrarily assigned a unitary value to each level of 
spinal cord segmentation: levels C 5 to T12 were assigned numeric values of 5 to 20. Analyses were performed using the Statview program, version 5.0.1 (SAS Institute Inc., Cary, NC, USA). The level of significance was set at $p<0.05$.

With the exception of the $\mathrm{FEV}_{1} / \mathrm{FVC}$ ratio, the mean values (in percentage of predicted) of the spirometry parameters were lower in the tetraplegic (cervical injury group) patients than in the paraplegic (thoracic injury group) patients ( $p<0.05$; Table 1). The correlation between the percentage of predicted FVC and the level of injury was significant $(r=0.631 ; p<0.001$; 95\% Cl: 0.323 to 0.818; Figure 1).

The mean values (observed and percentage of predicted) for MEP and MIP were lower in the cervical injury group than in the thoracic injury group, although the difference was not significant (Table 1). The mean SNIP value was lower for tetraplegic patients than for paraplegics patients $(p=0.011)$. When values were corrected for the predicted values, the difference between the groups remained ( $p<0.001$; Table 1). As can be seen in Figure 1, the correlation between the mean percentage of predicted and the level of injury was significant for MEP $(r=0.611$; 95\% Cl: 0.293 to 0.807$)$ and SNIP ( $r=0.489$; 95\% Cl: 0.125 to 0.737 ), although not for MIP $(r=0.246 ; 95 \% \mathrm{Cl}:-0.157$ to 0.578$)$.

Our findings show that SNIP is positively and significantly correlated with the level of injury. The spectrum of disturbance observed through FVC measurement was paralleled by that observed through SNIP determination, lower values for both parameters being obtained in tetraplegic patients. Neither MEP nor MIP was sensitive enough to differentiate tetraplegic patients from those with thoracic medullar inju-

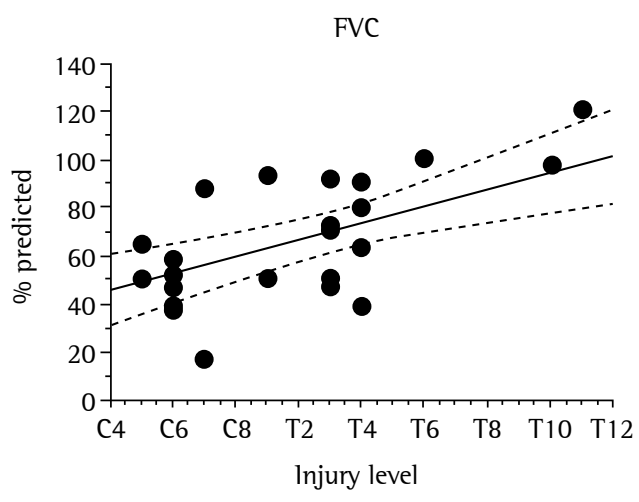

FVCpp $=31.667+3.491 * X ; r^{2}=0.398 ; p=0.0004$

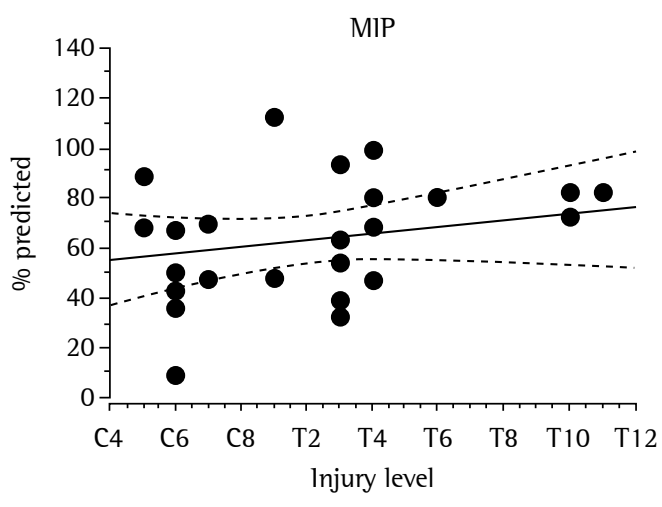

$\mathrm{MIPpp}=50.489+1.277{ }^{*} \mathrm{X} ; \mathrm{r}^{2}=0.06 ; \mathrm{p}=0.246$

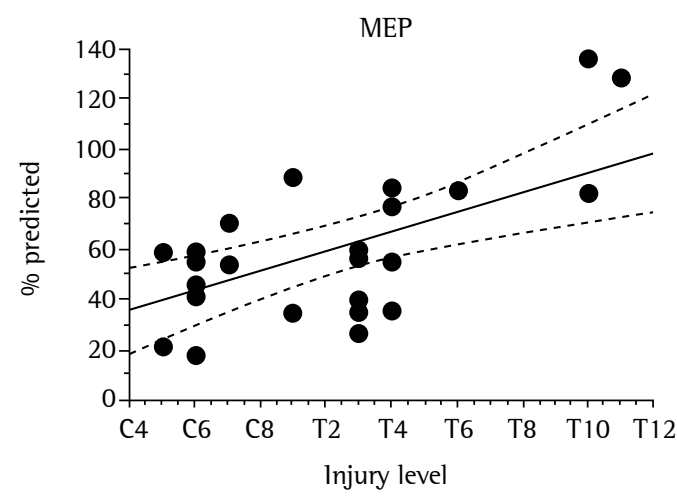

MEPpp $=20.054+3.908 * X ; r^{2}=0.374 ; p=0.0007$

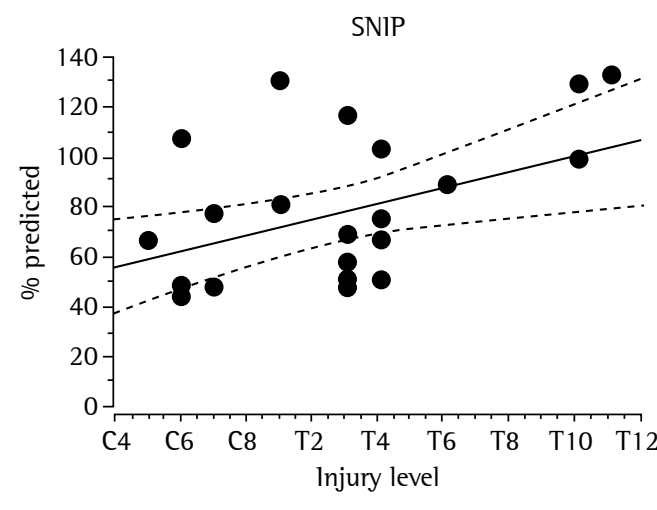

SNIPpp $=43.263+3.108{ }^{*} X ; r^{2}=0.239 ; p=0.0104$

Figure 1 - Linear regression curves and respective equations correlating the level of injury with the percentage of predicted (pp) values for FVC, MEP, MIP and sniff nasal inspiratory pressure (SNIP). Number of patients by level of injury: $\mathrm{C} 5=2 ; \mathrm{C} 6=6 ; \mathrm{C} 7=2 ; \mathrm{T} 1=2 ; \mathrm{T} 3=5 ; \mathrm{T} 4=4 ; \mathrm{T} 6=1 ; \mathrm{T} 10=2 ; \mathrm{T} 11=1 ;$ and T12 = 1 . Reference values adopted from the following studies: (for spirometry) Pereira et al. ${ }^{(16)}$; (for MIP and MEP) Neder et al. ${ }^{(15)}$; and (for SNIP) Uldry and Fitting. ${ }^{(17)}$ 
ries, and MIP failed to present any significant correlation with the exact level of injury.

Evaluating respiratory muscle strength in patients with neuromuscular disorders is challenging. Significant muscle weakness cannot be clinically excluded in such patients, even in those presenting normal or near normal lung volumes.$^{(8)}$ In addition, it is difficult to determine lung volumes in such cases, since it depends on patient cooperation and therefore adequate voluntary control. Respiratory muscle strength is typically evaluated on the basis of MIP and MEP, which must be interpreted with caution in individuals with neuromuscular disease. Low values (false-positive results) can be caused by inadequate patient effort, as well as by air leaks, fatigue or other factors. ${ }^{(11)}$

The invasive technique of measuring transdiaphragmatic and esophageal pressure during a sniff is considered the most accurate and reproducible method of evaluating the overall strength of the diaphragm. ${ }^{\left({ }^{(9)}\right.}$ Determination of SNIP is a noninvasive, accurate and reproducible alternative of assessing inspiratory muscle strength. ${ }^{(11)} \mathrm{It}$ strongly correlates with the esophageal pressure during a sniff in normal individuals and patients with skeletal and neuromuscular diseases. ${ }^{(9)}$ In patients with amyotrophic lateral sclerosis, SNIP has proven to be more sensitive than is FVC to measure minor changes in muscle strength and to predict the decline in respiratory function as the disease advances. ${ }^{(9)}$

To our knowledge, there have been no studies investigating the use of SNIP in patients with $\mathrm{SCl}$, although various studies have demonstrated the benefits of SNIP for evaluating patients with neuromuscular diseases. One study used transdiaphragmatic pressure during a maximal sniff, MIP and vital capacity in order to study the effect that different body positions and abdominal binders have on respiration in tetraplegic patients. ${ }^{(6)}$ The authors found no relationship between MIP and the various conditions tested. They stated that MIP was "too variable to be a valuable index of inspiratory power".(6) Another study involving 30 patients with cervical injury also found no relationship between MIP and the level of the injury. ${ }^{(18)}$

There are limitations to our study. We did not employ any gold standard test (e.g., esophageal pressure) as a comparison. In addition, the number of maneuvers could have been greater.
Furthermore, the possibility of a type 11 error exists, since there were only 5 patients with T6-T12 injury available for study. Moreover, a post hoc evaluation, using a one-tailed analysis and an alpha of 0.05 , found a power of less than $80 \%$ for MIP and MEP. Despite being underpowered, the study showed that SNIP was significantly better than MIP in discriminating the effect of $\mathrm{SCl}$ on inspiratory function. Another concern is the method we used to obtain the SNIP values. In most previous studies, SNIP has been measured in one nostril during a maximal sniff performed while leaving the contralateral nostril open. ${ }^{(19)}$ Since many patients with tetraplegia tended to make poor efforts and often needed encouragement, we chose to occlude the contralateral nostril, as advocated by Morgan et al. ${ }^{(9)}$ As recommended by the American Thoracic Society and the European Respiratory Society, ${ }^{(19)}$ we used the predictive equation devised by Uldry and Fitting ${ }^{(17)}$ for healthy subjects. Therefore, our percentage of predicted values might have been overestimated, which would tend to narrow any difference. Nevertheless, we observed a significant difference in SNIP between the groups, and SNIP values correlated with the level of injury, even when analyzed by Spearman's correlation coefficient. These methodological flaws would tend to reduce the chance of finding significant differences between groups, and we are therefore further encouraged that our results reflect real differences. However, our results are preliminary and must be interpreted with caution.

There are major differences between MIP and SNIP. ${ }^{(20)}$ It is of note that the procedures employed to determine these inspiratory pressures are not equivalent, since they are performed at different lung volumes. In addition, SNIP takes place during a ballistic effort, whereas MIP requires a supported effort. Determination of SNIP is an easy and natural procedure that allows the patients to activate their inspiratory muscles more completely than does MIP determination. Furthermore, inspiratory muscle activation patterns differ between the two procedures. ${ }^{(20)}$

Our preliminary results suggest that, in $\mathrm{SCl}$ patients, SNIP is a more accurate measure of inspiratory function than is MIP. Further studies might clarify this issue through comparison with a gold standard such as esophageal pressure measurement. Measurement of MIP at functional residual capacity should also be 
considered. Perhaps these maneuvers should be used in combination with spirometry for a complete sequential assessment of inspiratory muscle strength in $\mathrm{SCl}$ patients.

\section{Acknowledgments}

We would like to thank Luiz Guilherme Nadal Nunes, statistician in the Quality Control Sector of the SARAH Network of Rehabilitation Hospitals, SARAH-Brasilia, for the analytical assistance provided.

\section{References}

1. Winslow C, Rozovsky J. Effect of spinal cord injury on the respiratory system. Am J Phys Med Rehabil. 2003;82(10):803-14.

2. Linn WS, Adkins RH, Gong H Jr, Waters RL. Pulmonary function in chronic spinal cord injury: a cross-sectional survey of 222 southern California adult outpatients. Arch Phys Med Rehabil. 2000;81(6):757-63.

3. Roth EJ, Nussbaum SB, Berkowitz M, Primack S, Oken J, Powley S, et al. Pulmonary function testing in spinal cord injury: correlation with vital capacity. Paraplegia. 1995;33(8):454-7.

4. Badr C, Elkins MR, Ellis ER. The effect of body position on maximal expiratory pressure and flow. Aust $\mathrm{J}$ Physiother. 2002;48(2):95-102.

5. Tully K, Koke K, Garshick E, Lieberman SL, Tun CG, Brown R. Maximal expiratory pressures in spinal cord injury using two mouthpieces. Chest. 1997;112(1):113-6.

6. Goldman JM, Rose LS, Williams SJ, Silver JR, Denison DM. Effect of abdominal binders on breathing in tetraplegic patients. Thorax. 1986;41(12):940-5.

7. Mateus SR, Beraldo PS, Horan TA. Maximal static mouth respiratory pressure in spinal cord injured patients: correlation with motor level. Spinal Cord. 2007;45(8):569-75.

8. Fitting JW, Paillex R, Hirt L, Aebischer P, Schluep M. Sniff nasal pressure: a sensitive respiratory test to assess progression of amyotrophic lateral sclerosis. Ann Neurol. 1999;46(6):887-93.
9. Morgan RK, McNally S, Alexander M, Conroy R, Hardiman 0, Costello RW. Use of Sniff nasal-inspiratory force to predict survival in amyotrophic lateral sclerosis. Am J Respir Crit Care Med. 2005;171(3):269-74.

10. Soliman MG, Higgins SE, El-Kabir DR, Davidson AC, Williams AJ, Howard RS. Non-invasive assessment of respiratory muscle strength in patients with previous poliomyelitis. Respir Med. 2005;99(10):1217-22.

11. Stefanutti D, Benoist MR, Scheinmann P, Chaussain M, Fitting JW. Usefulness of sniff nasal pressure in patients with neuromuscular or skeletal disorders. Am J Respir Crit Care Med. 2000;162(4 Pt 1):1507-11.

12. Maynard FM Jr, Bracken MB, Creasey G, Ditunno JF Jr, Donovan WH, Ducker TB, et al. International Standards for Neurological and Functional Classification of Spinal Cord Injury. American Spinal Injury Association. Spinal Cord. 1997;35(5):266-74.

13. Standardization of Spirometry, 1994 Update. American Thoracic Society. Am J Respir Crit Care Med. 1995;152(3):1107-36.

14. Ashba J, Garshick E, Tun CG, Lieberman SL, Polakoff DF, Blanchard JD, et al. Spirometry-acceptability and reproducibility in spinal cord injured subjects. J Am Paraplegia Soc. 1993;16(4):197-203.

15. Neder JA, Andreoni S, Lerario MC, Nery LE. Reference values for lung function tests. 11. Maximal respiratory pressures and voluntary ventilation. Braz J Med Biol Res. 1999;32(6):719-27.

16. Pereira CA, Sato T, Rodrigues SC. New reference values for forced spirometry in white adults in Brazil. J Bras Pneumol. 2007;33(4):397-406.

17. Uldry C, Fitting JW. Maximal values of sniff nasal inspiratory pressure in healthy subjects. Thorax. 1995;50(4):371-5.

18. Gounden P. Static respiratory pressures in patients with post-traumatic tetraplegia. Spinal Cord. 1997;35(1):43-7.

19. American Thoracic Society/European Respiratory Society. ATS/ERS Statement on Respiratory Muscle Testing. Am J Respir Crit Care Med. 2002;166(4):518-624.

20. Nava S, Ambrosino N, Crotti P, Fracchia C, Rampulla C. Recruitment of some respiratory muscles during three maximal inspiratory manoeuvres. Thorax. 1993;48(7):702-7.

\section{About the authors}

\section{Andrea Ponte Rocha}

Physical Therapist. SARAH Network of Rehabilitation Hospitals, SARAH-Brasília, Brasília, Brazil.

\section{Sergio Ricardo Menezes Mateus}

Physical Therapist. SARAH Network of Rehabilitation Hospitals, SARAH-Brasília, Brasília, Brazil.

\section{Thomas Anthony Horan}

Thoracic Surgeon. SARAH Network of Rehabilitation Hospitals, SARAH-Brasília, Brasília, Brazil.

\section{Paulo Sérgio Siebra Beraldo}

Internist. SARAH Network of Rehabilitation Hospitals, SARAH-Brasília, Brasilia, Brazil. 